\title{
A rare case report of gestational trophoblastic disease in peri menopausal women
}

\author{
Nagashree U.*, Wahida Suresh
}

Department of Obstetrics and Gynaecology, Apollo Women's Hospital, Chennai, Tamil Nadu, India

Received: 11 August 2020

Accepted: 29 September 2020

\section{*Correspondence:}

Dr. Nagashree U,

E-mail: dr.nagashree@yahoo.com

Copyright: (c) the author(s), publisher and licensee Medip Academy. This is an open-access article distributed under the terms of the Creative Commons Attribution Non-Commercial License, which permits unrestricted non-commercial use, distribution, and reproduction in any medium, provided the original work is properly cited.

\begin{abstract}
Benign gestational trophoblastic disease (GTD) generally occurs in reproductive age group women; but is extremely rare in peri and post-menopausal women. We report a case of molar pregnancy in a 48-year-old lady with complaints of bleeding per vaginum with severe pain abdomen. The intention was to highlight the need to include GTD as a possible cause of abnormal bleeding per vaginum in peri and post-menopausal women. So early diagnosis and management with proper follow up is possible. It stresses the need for early recognition to avoid high malignant sequelae.
\end{abstract}

Keywords: Bleeding, Molar pregnancy, Magnetic resonance imaging

\section{INTRODUCTION}

GTD usually constitute benign conditions like complete and partial molar pregnancies; invasive mole/choriocarcinoma which are generally malignant; very rare placental site trophoblastic tumor. Benign GTD generally occurs in women of reproductive age group; but it is extremely rare in post-menopausal women. ${ }^{1-3}$ So it should be included in differential diagnosis of peri and post-menopausal bleeding to prevent delay in diagnosis and treatment as happened in this case.

\section{CASE REPORT}

A 49-year-old parous lady came with complaints of irregular periods with severe dysmenorrhea for 6 months. She had continuous on and off spotting from last 5 months followed by heavy bleeding since last 15 days. She has 2 children with no usage of any contraception method. There was no significant family history. She had no medical comorbidities.

Clinical examination revealed mass per abdomen of 16 weeks size. Urine pregnancy test was positive; serum beta human chorionic gonadotropin (HCG) was 102243 mIU/l. Transvaginal scan (Figure 1) showed an enlarged uterus with measurements $13.4 \times 6.3 \times 8.4 \mathrm{~cm}$ with thick endometrium. Heterogenous mass with cystic components measuring $9.6 \times 5.9 \mathrm{~cm}$ arising from lower end of anterior wall of uterus and seen occupying cervix. Mass does not reveal any vascularity. Both ovaries are normal.

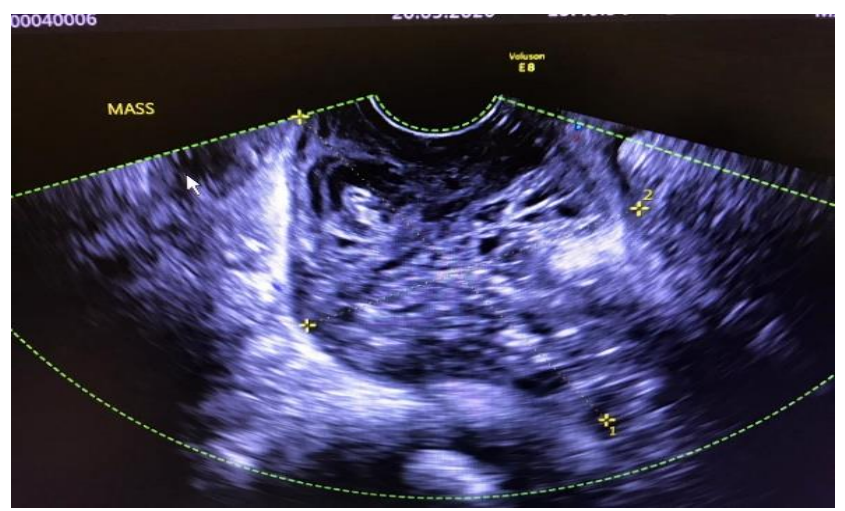

Figure 1: Snowstorm appearance on ultrasound. 
Magnetic resonance imaging (MRI) showed no myometrial involvement and products of conception (Figure 2). Proceeded with surgery- total abdominal hysterectomy with bilateral salpingo-oophorectomy. Intra operatively uterus was $16-18$ weeks size; cut section shows products of conception and surface shows haemorrhagic spots.

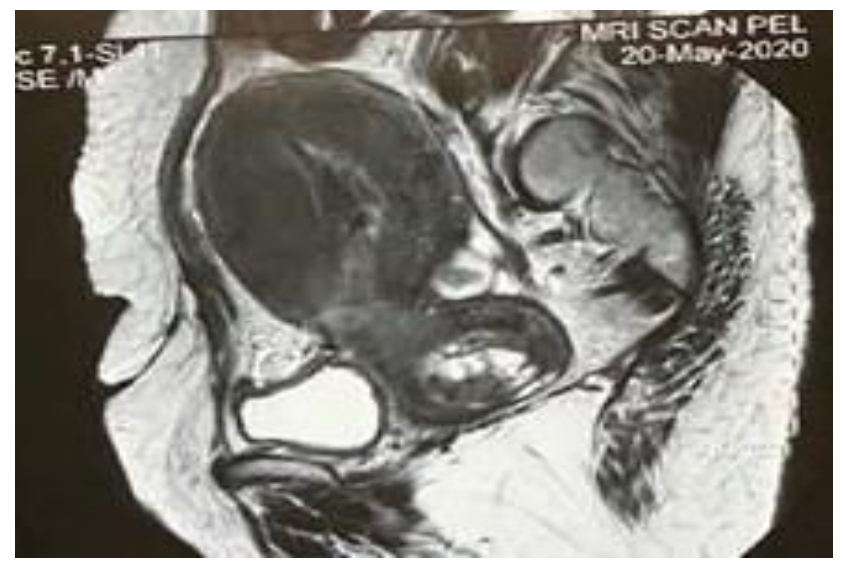

Figure 2: MRI of enlarged uterus with products of conception in the cervix.

Histopathological (HPE) report showed uterus with products of conception in situ. Uterus with extensive endometrial decidualization with polypoidal change and trophoblastic cells infiltrating endomyometrium. Villi infiltrate the endometrium. Trophoblastic proliferation involves less than half of the myometrium (Figure 3 and 4).

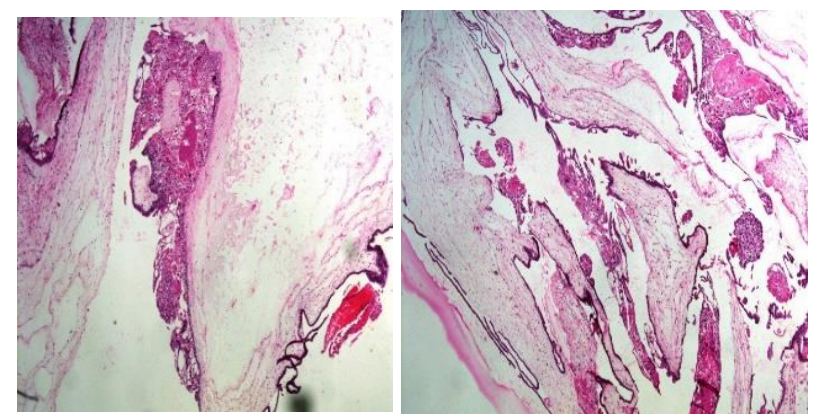

Figure 3: Decidual tissue with enlarged chorionic villi with marked cisternal change and villi exhibitting trphoblastic proliferation.

She was discharged on $2^{\text {nd }}$ POD with advice for regular follow up. She was asked every week to repeat beta HCG which was negative after a month. Her positron emission tomography (PET-CT) after 3 months is normal with every 3 months follow up.

\section{DISCUSSION}

Pregnancy is usually abnormal when happens beyond 50 years of age. ${ }^{4}$ The outcome could be spontaneous abortion/molar pregnancy. It is mostly malignant in post- menopausal age group but could be benign in peri menopausal age group as in our case. Gestational trophoblastic neoplasia constitutes invasive mole, choriocarcinoma, benign molar pregnancies with persistent elevation of beta HCG values. Molar pregnancies are subdivided into complete and partial moles based on the chromosomal pattern and histopathological evidence.

Complete moles (75-80\%) are diploid and androgenic due to dispermic fertilization of an empty ovum without any fetal tissue. Partial moles $(90 \%)$ are triploid in origin followed dispermic fertilization of an ovum, usually consist of fetal tissue. Placental site trophoblastic tumor (PSTT) is the rarest form of Gestational trophoblastic neoplasia (GTN) which arises from placental implantation following normal pregnancy/molar pregnancy/abortion. It might present as a slow growing tumor with regional metastasis initially followed by distant metastasis. In a literature review of 109 cases of GTD in women of more than 50 years age group by Jequier et al; they found malignant disease in $28.4 \%$; benign moles in $47.7 \%$ and unclear pathological diagnosis in $23.9 \%$.

Stanton estimates a 20 -fold increase in molar pregnancy in women more than 45 years age group.

\section{Clinical features}

GTD usually presents as abnormal vaginal bleeding in majority of the cases. Other symptoms could be nausea, abdominal pain, transvaginal expulsion of grape like vesicles, abnormally enlarged uterus, dyspnoea, haemoptysis, urinary retention or persistently elevated HCG titres in spite of molar evacuation. Sometimes they present with anaemia and hyperthyroidism. Hematogenous dissemination is the commonest-lung $(80 \%)$, vagina $(30 \%)$, brain $(10 \%)$ and liver $(10 \%)$.

\section{Diagnosis}

Initial diagnosis is based on multimodality approach like considering clinical features; serial beta HCG titres and pelvic imaging-like ultrasonography and MRI. The most possible reason for delayed diagnosis of GTD in perimenopausal age group could be the absence of suspicion of pregnancy in them. ${ }^{5}$ In a study conducted by Tsukamoto et al in women at 50 years with molar pregnancy-50\% developed invasive mole and 6\% developed choriocarcinoma. Evidence suggests that incidence of choriocarcinoma had decreased due to strict follow up of patients with molar pregnancy.

Ultrasound is first line of imaging. The appearance of lesion is classically described as snowstorm/granular appearance due to multiple echogenic foci. Pelvic MRI is used to assess depth of myometrial invasion and extra uterine spread in equivocal and complicated cases. Chest radiography, PET CT or brain MRI have been 
recommended as investigative tools for overall staging of the disease. Angiography has a role in management of disease complications with metastasis.

\section{Differential diagnosis}

Perimenopausal women presenting with lump in abdomen, bleeding per vaginum could raise suspicion of malignancy like endometrial carcinoma, ovarian carcinoma, leiomyosarcoma. Occasionally it could be just severe adenomyosis or large myoma uterus.

\section{Management}

Primary hysterectomy is the recommended treatment for molar pregnancy in $>40$-year age group due to high rate of malignant sequelae after molar evacuation $(56.3 \%)$ according to a study done by Tsukamoto et al. ${ }^{6}$

Close follow up with serum beta HCG is recommended. ${ }^{5}$ Prophylactic chemotherapy is controversial. ${ }^{7}$ Early detection of GTN is important as it has excellent prognosis following treatment due to its exquisite chemosensitivity.

\section{Follow up}

Serial beta HCG titres and imaging are done for serial follow up. CT scan is more sensitive than chest radiographs for diagnosis of lung metastasis. Liver metastasis has poor prognosis. Asymptomatic patients without lung metastasis unlikely to have brain metastasisthese usually do not require MRI/CT. Colour flow and spectral doppler are mostly performed for diagnosing primary and recurrent GTD and post treatment follow up.

\section{CONCLUSION}

GTD should be considered in the differential diagnosis of peri and postmenopausal vaginal bleeding.

In menopausal women, definitive treatment should be hysterectomy owing to high risk of malignancy. A high level of suspicion should be included in differential diagnosis of peri menopausal bleeding to prevent delay in diagnosis and treatment.

Long term follows up with beta HCG needs to be done to detect recurrence.

Funding: No funding sources

Conflict of interest: None declared

Ethical approval: Not required

\section{REFERENCES}

1. Garcia M, Romaguera RL, Gomez-Fernandez C. A hydatidiform mole in a postmenopausal woman: A case report and review of the literature. Arch pathol lab med. 2004;128(9):1039-42.

2. Goedhals J, Botha MC, Theron M, Beukes CA. Complete hydatidiform mole in a 57-year-old woman. South Afri J Obstet Gynaecol. 2010;16(1):22-3.

3. Lok CA, Zürcher AF, Van Der Velden J. A case of a hydatidiform mole in a 56-year-old woman. International J Gynecol Cancer. 2005;15(1):163-6.

4. Miletić T, Aberle N, Mikulandra F, Karelović D, Zakanj Z, Banović I et al. Perinatal outcome of pregnancies in women aged 40 and over. Collegium antropologicum. 2002;26(1):251-8.

5. Bandy LC, Clarke-Pearson DL, Hammond CB. Malignant potential of gestational trophoblastic disease at the extreme ages of reproductive life. Obstet Gynecol. 1984;64(3):395-9.

6. Davidson SA, Gottesfeld J, La Rosa FG. Molar pregnancy in a 60-year-old woman. Int J Gynecol Obstet. 1997;56(1):53-5.

7. Koga K, Maeda K. Prophylactic chemotherapy with amethopterin for prevention of choriocarcinoma following removal of hydatidiform mole. Am J Obstet Gynecol. 1968;100(2):270-5.

Cite this article as: Nagashree U, Suresh W. A rare case report of gestational trophoblastic disease in peri menopausal women. Int J Reprod Contracept Obstet Gynecol 2020;9:4716-8. 